\title{
Justifying Public Decisions in Arctic Oil and Gas Development: American and Russian Approaches
}

\author{
NICHOLAS E. FLANDERS, ${ }^{1}$ REX V. BROWN,,$^{2}$ YELENA ANDRE’EVA ${ }^{3}$ and OLEG LARICHEV ${ }^{3}$
}

(Received 28 February 1997; accepted in revised form 29 January 1998)

\begin{abstract}
Government resource decisions in the Arctic typically involve complex issues; multiple criteria are used to choose among alternatives. This complexity is even greater with petroleum development because of concerns about national energy security, environmental impacts, and economic development. Two decision-aiding techniques may help decision makers clarify their decisions to themselves, the stakeholders, and the general public. The Russian qualitative technique seeks to reduce the number of criteria and find alternative options that may be better than the initial ones. The Western quantitative technique seeks to measure the decision maker's judgement about the utility and certainty of each option. These techniques are applied to two case studies: a decision about gas pipeline routing on the Yamal Peninsula, Russia, and a tool for evaluating applications for development permits on the North Slope of Alaska. The qualitative method is easier to use and may be the best model for people who use numbers infrequently or want to make a claim based on rights. The quantitative method did well at preserving detail and incorporating uncertainty. Both approaches helped to reduce the apparent complexity of the decisions.
\end{abstract}

Key words: oil and gas, decision analysis, Yamal Peninsula, Badami, Niakuk

RÉSUMÉ. Les décisions gouvernementales concernant les ressources dans l'Arctique mettent le plus souvent en jeu des questions complexes; un grand nombre de critères sont utilisés en vue de choisir parmi différentes options. Cette complexité s'accroît dans le cas de l'exploitation pétrolière en raison des problèmes entourant la sécurité nationale de l'énergie, les retombées environnementales et le développement économique. Deux techniques d'aide à la décision peuvent inciter les décideurs à clarifier leurs décisions pour eux-mêmes, pour les parties intéressées et pour le grand public. La technique qualitative russe cherche à réduire le nombre de critères et à trouver des solutions de rechange qui pourraient être meilleures que les mesures initiales. La technique quantitative occidentale cherche à mesurer le jugement du décideur sur l'utilité et la certitude de chaque option. Ces techniques sont appliquées à deux études de cas: une décision concernant le tracé d'un gazoduc dans la presqu'île de Iamal en Russie, et un outil permettant d'évaluer les demandes de permis d'exploitation sur le versant Nord de l'Alaska. La méthode qualitative est plus facile à utiliser et peut être le meilleur modèle pour des individus qui n'ont pas l'habitude des chiffres ou qui veulent établir une revendication fondée sur des droits. La méthode quantitative réussit bien à préserver le détail et à intégrer l'incertitude. Les deux approches aidaient à réduire la complexité apparente des décisions.

Mots clés: pétrole et gaz, analyse des décisions, presqu'île Iamal, Badami, Niakuk

Traduit pour la revue Arctic par Nésida Loyer.

\section{INTRODUCTION}

The world's desire for oil and gas has led to the exploration and development of fields in the remote corners of the earth. The importance to developed economies of petroleum for transportation, electrical generation, and temperature control has made supervision of these resources matters of national and international security. However, development has proved controversial in areas where the natural environment is considered particularly valuable or vulnerable.

The development of petroleum fields in the Arctic is a case in point. The world-class discovery of the Prudhoe Bay oil field in Alaska should have been followed by immediate development and operation. Instead, a nascent environmental movement held up exploitation for several years. Only the Arab oil boycott in 1974 convinced the United States Congress to remove all environmental roadblocks and allow the construction of the Trans-Alaska Pipeline System. In Russia, the central government has decided to develop gas fields on the Yamal Peninsula because of a national need for foreign exchange. This decision was made despite an expert commission report that raised serious environmental and indigenous rights concerns.

Whether to develop new fields in the Arctic, and under what conditions, has become a national and international issue. The terms of this debate involve complex concerns tied

\footnotetext{
${ }^{1}$ Institute of Arctic Studies, Dartmouth College, 6214 Steele Hall, Hanover, New Hampshire 03755-3577, U.S.A.; nicholas.flanders@dartmouth.edu

${ }^{2}$ The Institute of Public Policy, George Mason University, Fairfax, Virginia 22030-4444, U.S.A.

${ }^{3}$ Institute for Systems Analysis, Russian Academy of Sciences, 9, pr. 60 let Octjabrya, 117312 Moscow, Russia

(C) The Arctic Institute of North America
} 
up with multiple factors that must be taken into account. A clear-cut answer rarely emerges even when "the national interest" is considered paramount. A major difficulty derives precisely from defining what the national interest is. This complexity is true of many environmental debates, but becomes most obvious when, as in the Arctic, the issue pits fundamental needs of the economy and society, such as transportation, against fundamental symbols of environmental purity, such as the sparsely inhabited polar regions.

\section{The Need for a Reviewable Rationale}

The need for a reviewable rationale now exists in both Russia and the United States. The need in the United States has existed since at least the passage of the National Environmental Policy Act (NEPA) in 1969. Alaska was the site of perhaps the first environmental impact review, which predated NEPA by almost a decade (O'Neill, 1994). NEPA, as well as several acts that have followed, requires a multiagency and public review of the environmental impacts of a proposed federal action. Single agencies continue to make decisions about those actions, but they must explain their preference and fully answer objections put forth by other agencies and the public.

In Russia, the situation is now similar. In Soviet times, many Arctic problems were declared "secret" for military reasons. Central ministries were the dominant decision makers. Now, the government must explain decisions about Arctic resources to the general population and active groups. The decisions must be well prepared, logical, and rational to establish why the selected option is the best. The need to use decision analysis is new for government administrators in Russia, where the tradition of authoritarian rule is strong. Every application of decision analysis has special value under Russian conditions: the analysis must continually demonstrate its usefulness to all participants in real decisionmaking processes.

In the United States, despite a longer history of open decision making, resource decisions in the Arctic still appear to be ad hoc or politically motivated. In either case, a broadly understandable, reviewable rationale is missing. The result can be political and legal battles in which the facts and public interest are buried beneath slogans and simplified images. Clarification of a decision, therefore, can improve the decision-making process: the decision maker can show that the decision was based on full consideration of the issues, and the public and stakeholders can see where the key issues lie. Because knowledge of the Arctic is generally lacking at the national level in most nations, clarity can result in both better decisions and a better-informed public.

\section{The Structure of This Study}

This paper considers how natural resource decisions, particularly related to oil and gas development, can be clarified, justified, or improved. The research had two principal components.
One component was to review and evaluate available methods for analyzing and guiding the decision-making process. In this component, we compared a quantitative approach familiar in the West with a Russian qualitative approach. Each approach organizes the data, knowledge, and value judgements the decision makers would normally use in a structured, transparent way that clarifies the options, arguments, and implied decision. Both approaches are intended to enhance the perceptions of individual decision makers. They are not attempts at objective analyses. Both methods, especially the quantitative one, have been widely used throughout the world to make sounder public and other decisions and to communicate their grounds and assumptions to interested parties (Brown, 1987; Larichev et al., 1995).

The other component of the research was to develop these approaches into a concrete methodology adapted specifically to Arctic natural resource decisions and to test them on real cases in Siberia and Alaska, both past and present. The Russian team, Andre' eva and Larichev, carried out the fieldwork and qualitative decision analysis of the Yamal case. Everyone participated in the fieldwork associated with the Alaskan permitting case, but the American and Russian teams carried out separate analyses according to their respective quantitative and qualitative methods.

We discuss oil and gas development in the Arctic as an example of major natural resource decisions and the role of decision aids in clarifying how those decisions are made. We then give the Russian and American case studies. The former addresses a single decision: whether to pipe gas from the Yamal Peninsula over the land or under the sea. The latter addresses a class of decisions: what procedure federal regulators should adopt in deciding whether to permit oil and gas construction projects in Alaska. Finally, we discuss general implications for the Arctic natural resource decision process.

\section{BACKGROUND: ARCTIC OIL AND GAS DEVELOPMENT}

\section{Russia}

Soviet gas development during the 1970s and 1980s was a specific effort to create a "gas bridge" between the present use of oil to produce energy and a nuclear and coal future. Gustafson (1989) argues that the development of gas was necessary following many years in which the centrally planned economy needed expanding oil production to survive. The opening of the Western Siberian fields and the construction of pipelines that would carry gas to Western Europe transformed the industry. Gas produced $40 \%$ of export earnings by the late 1980s. The Soviet Union expanded gas production by $50 \%$ in five years starting in 1980-81, an expansion that required a huge commitment of resources and development in Arctic areas. The original idea, held in the late 1970s, had been to develop the northern fields simultaneously with Urengoy, Russia's largest gas field. The cost of development, the lack of foreign capital, and the sudden decision to expand 
gas production dictated that all resources be aimed at the large, more southern field. Thus, the development of Yamburg and Yamal, the northern fields, was postponed.

By the late 1980s, when the more northern fields were needed to continue meeting targets, conditions had changed. In 1989, a report from a state expert panel raised questions about the environmental consequences of gas pipeline construction on the Yamal Peninsula (Expert Commission, 1989). This report held up construction of the pipeline that would carry gas from the Yamal fields (Fig. 1). Then the collapse of the Soviet Union and the ensuing economic turmoil intervened. In 1993, it was apparent that the income from gas production was a necessity for the Russian economy, but gas production had actually declined. President Yeltsin made the decision to develop the pipeline and open the fields for production. National economic security overrode other considerations. The only question that remained was which pipeline route would be used to move the gas to European markets. The pressure to develop these fields increased as gas production continued to fall in 1994 and 1995.

But national environmental groups, some with international backing, have begun to play a role familiar in Western petroleum development cases. Those responsible for both development and regulation now find themselves in a position where their decisions require justification to a much broader audience than during the Soviet period.

\section{The United States}

In December 1968, an oil company discovered the largest oil field ever found in North America at Prudhoe Bay on the North Slope of Alaska (Fig. 2). A pipeline was needed to transport the oil to the ice-free port of Valdez in Prince William Sound more than $1000 \mathrm{~km}$ away on the southern coast. Alaska Native land claims and environmental concerns held up construction for almost five years.

Congress removed these roadblocks, first by the passage of the Alaska Native Claims Settlement Act of 1971, then by overriding the environmental concerns in response to the Arab oil boycott of 1973-74. The United States, dependent on oil imports, had been vulnerable to the boycott. A large field on domestic territory held the attraction of regaining control over the country's supply. The boycott experience convinced the American public that domestic sources of oil were important to the national weal. From the time that the pipeline began to carry oil in 1977 until the late 1980s, when lower prices and field depletion led to declining domestic production, the United States produced over half of the oil it consumed (Flanders, 1993). The development of the pipeline and the North Slope fields appeared to be a successful national policy.

In the 1980s, however, the environment reappeared as a counterconcern. The conflict settled on the coastal plain of the Arctic National Wildlife Refuge (ANWR). Congress had understood the potential of the refuge for petroleum when officially recognizing it in the Alaska National Interest Lands Conservation Act of 1980: Section 1002 of the Act left open the possibility that the coastal plain could be explored and developed.

Allowing oil development in a wildlife refuge provided a powerful environmental cause, and environmental groups staged an effective campaign against development. In 1991, Congress voted against ANWR development. The decision was not final, however. Both sides, environmentalists and industry, see permitting decisions on smaller fields as skirmishes preliminary to another ANWR battle.

The state and regional governments have also benefited from North Slope development. Since 1977, Alaska has earned over $80 \%$ of its income from the oil industry. As production declines on the North Slope, state revenues will fall. The North Slope Borough taxes both real estate and personal property, which means that it receives revenue on the value of both the lease-hold and the equipment at the oil fields. The borough has also taken on substantial debt. Its future ability to pay its creditors depends upon continuing oil production within the borough.

\section{DECISION ANALYSIS}

Decision analysis is a broad paradigm for the systematic evaluation of alternative actions, based on all available information, as a basis for choice among them. Its purpose is normally to make decisions better and clearer. Its inputs capture the knowledge and judgement of decision makers: their perception of what the options are, what the options' consequences might be, and the relative importance of criteria characterizing these consequences. The class of decisions involved here concerns two or more discrete options that can be evaluated according to two or more criteria.

Decision analysis has two variants: qualitative and quantitative. Qualitative or categorical decision analysis (CDA) relies on natural language and non-numerical categorization of the considerations in a choice. Quantitative or numerical decision analysis (NDA) represents uncertainty and value in the form of numbers and combines them in a quantitative model (derived from statistical decision theory). The qualitative analysis has been associated with Russian decision analysis; the quantitative, with Western decision making. The two approaches may draw out different aspects of the same problem.

\section{The Russian Approach}

Descriptions of the methodological base of CDA are in Larichev (1987, 1992) and Larichev and Moshkovich (1997). CDA tries to use the natural language of the decision maker, active parties, and potential experts to structure a problem. The goal of structuring is to define the criteria to be evaluated for the initially given options. For each criterion, an evaluation scale is constructed with a small number of quality grades ranging from best to worst. These are drawn from natural language, for example, "no damage to the environment"; "moderate damage to the environment"; "major damage to 


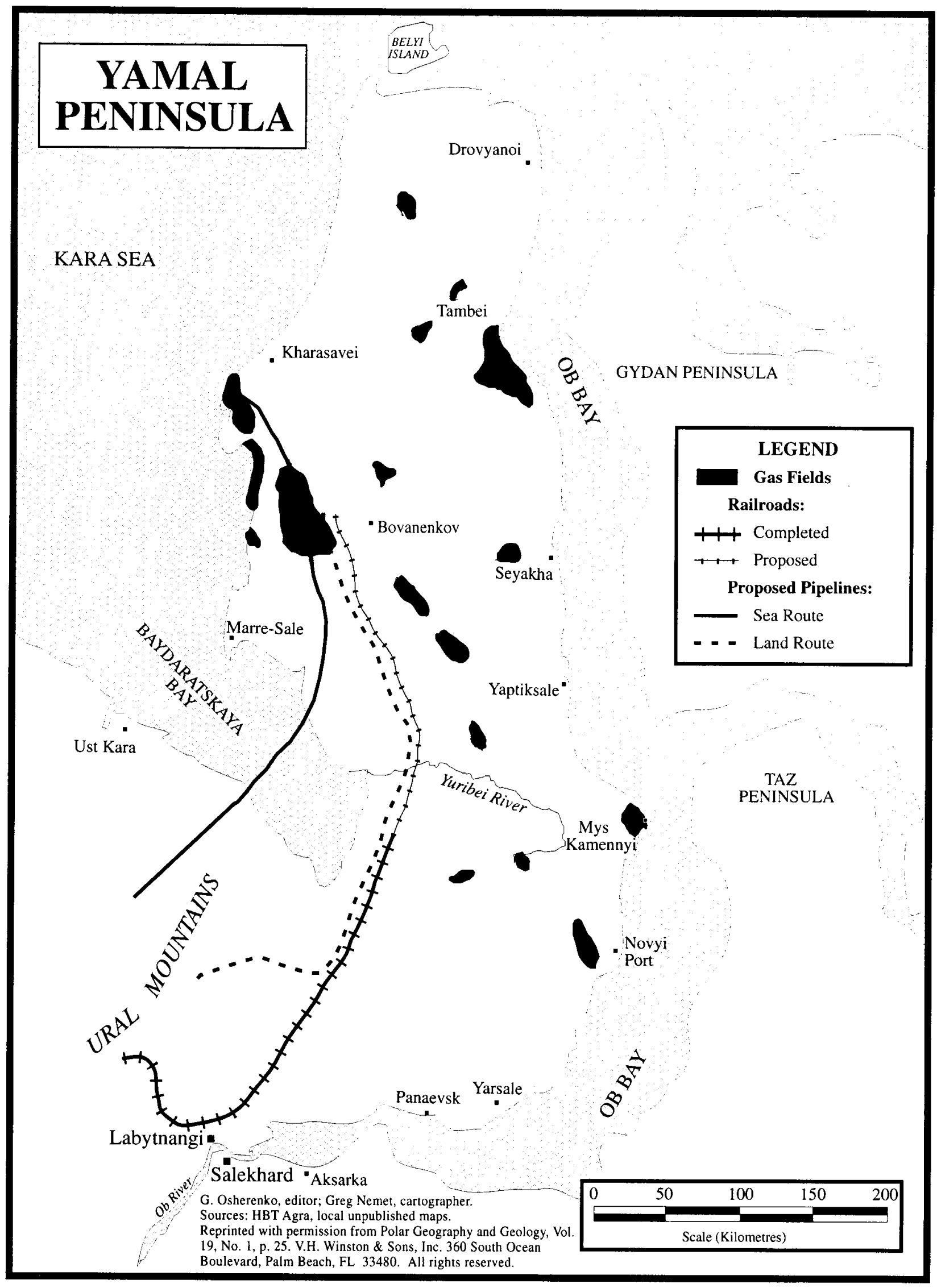

FIG. 1. Proposed pipeline routes and gas fields, Yamal Peninsula, Russia. The sea route (solid line) crosses Baydaratskaya Bay from the Bovanenkova field. The land route (dashed line) follows the proposed railway line around the bay. 
Based on: http://www dnr. state.ak.us/oil/data/carto/cns 1 m. git. Used with the permission of Alaska Department of Natural Resources, Division of Oil and Gas.

All rights reserved.

\section{Beaufort Sea}

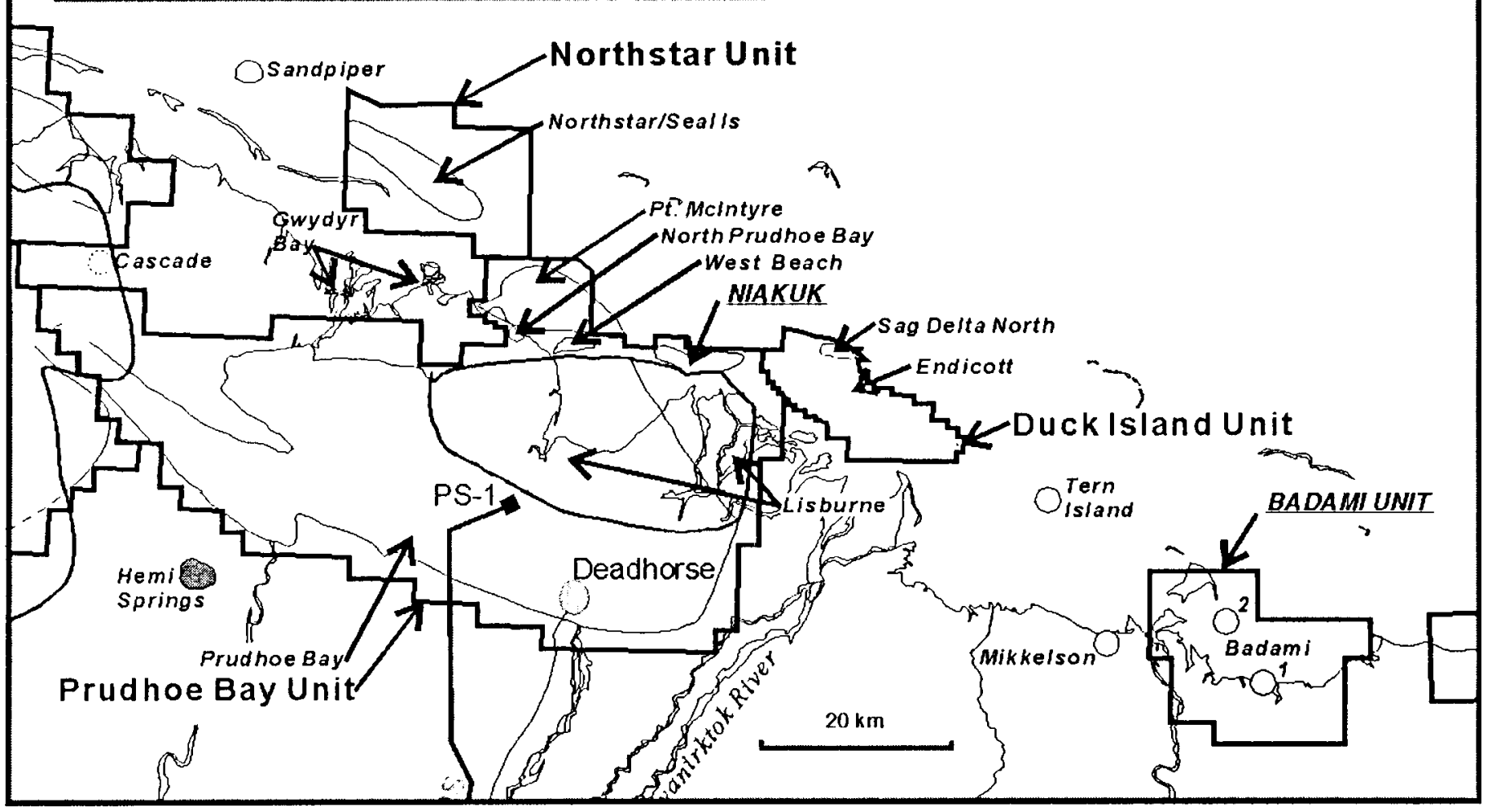

FIG. 2. Major oil fields, North Slope, Alaska, USA. The Niakuk and Badami fields are noted by underlining and italics.

the environment." When major measurement difficulties exist, relative (rather than absolute) evaluations of the options are recommended (Oseredko et al., 1982; Huber and Huber, 1987).

Larichev and Moshkovich (1997) describe the special methods CDA uses for comparing alternatives through these verbal evaluations. Pair-wise compensation is one such method: used when the initially given options are few; it compares the options qualitatively, pulling out their relative merits and deficiencies. At every stage of the decision process, CDA helps the decision maker reduce the decision to a more manageable size. For instance, evaluations on criteria that are not really different are eliminated. By this means, the number of evaluative criteria for comparison is reduced.

This method then tries to find a condition where the disadvantages of one option outweigh the disadvantages of the other. First, the decision maker ranks the disadvantages of the two options separately. Then special reference options are created and presented to the decision maker. The options have the same number of criteria as the original problem, but they only retain the original, real differences in one or two criteria. For the other criteria, both options put forward the best (or worst) evaluations. The decision maker is then asked to choose between the two reference options. Put another way, the decision maker is asked: Given the other criteria being equal, which of these two options would you prefer when they differ on these two (or one) criteria? When comparing the reference options, the decision maker goes through the pairwise comparisons and, for each pair, chooses one option's disadvantages over those of the other. If all the disadvantages of one option are found to be less harmful than those of the other, the problem is solved. When comparing the two reference options, the decision maker performs a psychologically valid operation (Larichev, 1992).

When only doing qualitative comparisons, one can end up with a situation of noncomparability. Noncomparability occurs when some evaluations are better for the first option and some better for the second. To resolve this problem, a new, more promising option is sought that could be better than the two initially given. The method used helps the decision maker to find the minimum changes needed in the evaluations of existing options to create a new, better alternative.

In Russia, as in the United States, many active groups participate in Arctic-related decisions, including local authorities, the local population, and the company responsible for construction. In the post-Soviet period, reaching agreement among all active groups is a necessity. Decision analysis plays a special role in Russian Arctic problems by examining the positions of different active groups, identifying the favored alternative for each group, and preparing for negotiations 
among them. The same analysis is carried out with all the different active groups, and differences in positions are analyzed. New options are developed with the idea of finding agreement among groups.

\section{The American Approach}

Numerical decision analysis (NDA) essentially translates judgement and knowledge relevant to evaluating some choice into a quantitative model (Raiffa, 1968; Zeckhauser et al., 1996). Normally, NDA calculates a numerical value for each option, so that the best option is clear. For example, probability and utility values are attached to each possible consequence of an option, and the option with the highest probability-weighted expected utility is logically preferred. This type of model often suits a case where uncertainty is critical.

In many environmental management decisions, the critical issue is conflicting objectives, and another common model often works well. The competing criteria are listed along with the decision-maker's numerical judgement of their relative importance. The impact of each option on each criterion is evaluated separately from the importance of each criterion. The preferred option is the one with the highest importance-weighted impact. High impact in areas of little importance can balance out small impact in areas of great importance.

An NDA approach is normally comprehensive: it should characterize all considerations (values and assessments) relevant to a choice, even if at a highly aggregate level. For example, an importance-weighted impact model does not attempt to reduce the number of criteria per se, though it may group them into fewer classes.

The NDA may use qualitative assessments and natural language preparatory to developing numerical values. This qualitative step may prove all that is necessary, and leaders in the field recommend it.

The differences between the two approaches may be seen through specific applications. The literature is largely limited to comparisons of verbal and numerical treatments of the uncertainty aspect of decision analysis (Erev and Cohen, 1990; Rapoport et al., 1990; Hamm, 1991; Wallsten et al., 1993).

\section{THE RUSSIAN CASE: GAS TRANSPORT FROM YAMAL}

\section{Background}

As noted, the development of the Yamal gas fields has become a matter of national importance. However, this development has many unresolved problems. An essential one is the choice between two routes connecting the gas fields to the existing gas pipeline system. A senior Russian official wanted to get reliable confirmation that RAO Gazprom's preliminary choice was the best. RAO Gazprom is the joint stock company developing the project. The Russian authors of this paper have been working with various stakeholders in the decision. During the development of the project, the idea of straightening the pipeline route by crossing Baydaratskaya Bay (the sea route) received strong support. The second option (the land route) would cross the Yamal Peninsula to the east of the bay. The choice has been the subject of bitter discussion between two project institutes over several years. The gas project institute Giprospetsgaz in St. Petersburg favored the land route, but the gas project institute Yusniiprogaz in Donetsk (Ukraine) proposed crossing the bay. Both institutes have arguments for and against the sea and land routes. The decision and the start of pipeline construction were recently postponed, partly because of the complexity of this choice.

Thus, the task is one of decision making with two options. This problem concerns unknown natural conditions, the interests of different groups influencing the choice, and contradictory appraisals of the alternatives on various criteria, as well as other things. For a more detailed description of this case, see Andre'eva et al. (1995).

\section{Two Options}

The two options are the sea route crossing the bay and the land route. The following distinguishing characteristics or criteria were initially included in the analysis: (1) length of the route; (2) terms of construction; (3) time for construction; (4) cost of construction; (5) impact on the environment; (6) risk of a pipeline rupture accident; (7) consequences of a pipeline rupture accident; (8) time needed to recover from an accident; and (9) uncertain and unknown factors. With respect to (6), the option of crossing Baydaratskaya Bay involves unique features that could cause an accident: (a) the instability of the shore because of permafrost processes and sea ice impact; (b) the rupture of or damage to the pipeline through ice scouring; and (c) the capability of icebergs to reach Baydaratskaya Bay. With respect to (9), the analysis points out that the decision must be made under conditions of major uncertainty because the construction start date has been set for the near future.

\section{Active Groups}

Before comparing the two options, we must analyze who will make the choice and how. A single decision maker is not likely to make the decision because of the high project cost. On the contrary, several institutions and organizations, or "active groups," are taking part directly or indirectly in the decision. They are: (1) RAO Gazprom, which ordered the development of the project and must evaluate and confirm the pipeline route, and its operational division in North Siberia, Nadymgazprom; (2) the two project research institutes that developed the two options; (3) two government ministries, the Ministry of the Economy, which evaluates the project's economics, and the Russian Federation Committee for the Protection of the Environment and Natural Resources, which evaluates its ecological effects; (4) the local authorities in the 
Yamal region, who must give their agreement to one option of the pipeline; and (5) local communities and representatives of Native peoples, whose territory and resources will be affected by the construction of the pipeline system. The active groups have different interests, and one might expect that the groups would support different options.

\section{The Application of Russian CDA to the Yamal Case}

It is logical to take into account only the criteria for which one can find an essential difference between the options. For example, the preliminary estimate shows that the required construction time is 5-7 years for both options. The unstable national economic situation can affect the starting time. Because this problem exists for both options, the analysis can ignore the problem, as it is not relevant to a choice between the two. Route length, time of construction, and terms of construction can be considered under the criterion "cost." The terms of construction can also be considered under "probability of an accident," since difficult conditions can affect the quality of construction and hence increase the likelihood of a future accident. The relevant criteria and their evaluations are shown in Table 1:

1. Cost. The cost of crossing Baydaratskaya Bay $\left(\mathrm{C}_{\text {sea }}\right)$ was determined by a foreign firm that is ready to construct this part of the pipeline. The initial estimates show that $\mathrm{C}_{\text {sea }}$ is a little higher than $\mathrm{C}_{\text {land }}$.

2. Ecological impact. Both options would have a negative impact on the environment. Though the sea option contains some uncertainty, ecological impact is much larger for the land option: a land pipeline would cross a lot of land and many rivers.

3. Probability of accident. Because of unstable shores and the possibility of ice scouring, the probability of an accident is higher for the sea option.

4. Consequences of the accident. An accident on land is usually connected with an explosion and destruction of the environment. A sea accident would not cause an explosion, but the gas would rise through the water and cracks in the ice. The land option is clearly worse.

5. Reliability of gas supply. The repair of the pipeline after an accident would require much more time under the sea option, particularly since the bay is ice-free for only 60-70 days per year. The sea option is clearly worse.

6. Uncertain and unknown factors. Many more uncertain and unknown factors are connected with the realization of the unique project of crossing Baydaratskaya Bay. The sea option is clearly worse.

These comparative, qualitative evaluations are practically all we can measure; other qualitative measurements are more difficult. How does one draw conclusions with such weak measurements?

As noted, CDA methods do not guarantee that pair-wise comparisons of the disadvantages of two alternatives will always lead to a clear preference. This situation resulted with
TABLE 1. CDA analysis of gas pipeline routes from the Yamal Peninsula (Russia).

\begin{tabular}{lcc}
\hline \hline Criteria & Sea Option & Land Option \\
\hline Cost & $\mathrm{C}_{\text {sea }}$ & $\boldsymbol{C}_{\text {land }}{ }^{1}$ \\
Ecological impact & $\boldsymbol{E}_{\text {sea }}$ & $\mathrm{E}_{\text {land }}$ \\
Probability of accident & $\mathrm{P}_{\text {sea }}$ & $\boldsymbol{P}_{\text {land }}$ \\
Consequences of accident & $\boldsymbol{A}_{\text {sea }}$ & $\mathrm{A}_{\text {land }}$ \\
Reliability of gas supply & $\mathrm{R}_{\text {sea }}$ & $\boldsymbol{R}_{\text {land }}$ \\
Uncertain and unknown factors & $\mathrm{U}_{\text {sea }}$ & $\boldsymbol{U}_{\text {land }}$ \\
\hline \hline
\end{tabular}

${ }^{1}$ The favored option according to each criterion is indicated by bold italics, e.g., $\boldsymbol{C}_{\text {land }}$ indicates that the land option is less costly.

the two Yamal pipeline options. The greater uncertainty and lesser reliability of gas supply for the sea option were worse than the ecological impact from the land option. But the negative consequences of an accident under the land option were worse than the greater probability of an accident under the sea option. The research team, working with the decision makers and experts, undertook the development of a new, more promising option from the existing ones.

A method for aiding strategic choice called ASTRIDA (Berkeley et al., 1991) was employed to define a new and potentially best option. In the case of incomparability, ASTRIDA proposes the modification of one existing option. That is, the method asks the question: what needs to be changed in one option to make it clearly equal to or better than the other option? Below is the analysis corresponding to the interests of $R A O$ Gazprom.

A new sea route option resulted from the search for ways to change the characteristics of the sea route. Discussions with experts suggested ways in which the negative aspects of that option could be removed:

To eliminate problems from seashore instability, the pipeline could be put through special shafts at a safe distance from the shore. This construction would incur additional costs $\left(\mathrm{C}_{\text {shafts }}\right)$.

To avoid damage to the pipeline from ice scouring, the pipeline could be laid in special trenches $1.5-2 \mathrm{~m}$ deep. As these trenches would be deeper than those called for in the project plan, the costs $\left(\mathrm{C}_{\text {trenches }}\right)$ would also be additional.

To eliminate the danger from icebergs, a special observation service and a ship to drag an iceberg away would be used. The cost of the service and ship is denoted by $\mathrm{C}_{\text {ice }}$.

Adding these features to the sea option creates a new alternative with an element of uncertainty that is approximately equal (from the point of view of the experts) to that of the traditional land option. With the development of a special repair service for the underwater pipes, the reliability of the gas supply could be made equal. Thus, no significant differences would exist between the sea and land routes except cost and ecological impact. The cost of the new sea option $\left(\mathrm{C}_{\text {sea }}+\right.$ $\mathrm{C}_{\text {shaft }}+\mathrm{C}_{\text {trenches }}+\mathrm{C}_{\text {ice }}$ ) would clearly be higher and the land option would still create greater environmental destruction. But now the comparison can be considered as one between higher costs (sea) and lower environmental protection (land). The comparison between two factors presents a real, crucial choice to be made. 
Analogous analyses were made from the positions of other active groups. The development of a new option was useful in this case, too. With regard to the two initial options, only the positions of the local authorities and local population were clear: they supported the sea option. The new sea option was also more attractive to the Russian Federation Committee for the Protection of the Environment and to Nadymgazprom. But, the positions of Gazprom and the Ministry of the Economy in the final, crucial choice presented above were influenced by the difficult financial situation in Russia. The Ministry was inclined toward the less costly land route.

\section{The Influence of Recommendations}

Our report, with the recommendations presented above, was given to RAO Gazprom. At that time, the original sea option was more attractive to the majority of the organization's managers. The intention to begin pipeline construction was strong, and they had expected that the report would support this option. Instead, the report added doubts about its acceptability, and construction was postponed. One reason was the uncertain and unknown factors described by the report. During the delay, new investigations were undertaken on the problem of seashore instability and ice regimes in Baydaratskaya Bay. These studies were an objective confirmation that the available data were insufficient to ensure safe operations.

That delay has now turned into a cancellation. Market prices have been too low, problems of investment remain unresolved, and drilling in an unstable sandy-permafrost surface still presents complex engineering challenges. AMOCO, which had a major interest in the area, has pulled out completely. It appears that the fields will not be developed until 2005, and liquid natural gas (LNG) ships are under assessment as an alternative to pipelines for transporting gas out of the region when development does take place.

\section{Possible NDA of the Yamal Case}

NDA could be attempted on the same problem. Larichev et al. (1995), for example, present a hypothetical "importance-weighted impact" model based on the same set of criteria: cost, ecology, accident risk, etc. However, instead of presenting the perspective of each active group (as in the above CDA), the model could represent the view of someone wishing to decide which pipeline route best served the nation's interest or to argue the case before a public audience. For example, a responsible citizen or government official might supply the impact and importance inputs, and the conclusions would be attributed to that person.

The evaluation scale was from 0 to -100 , where 0 is no impact of any kind, and -100 is the worst plausible impact under a particular criterion. On one illustrative set of inputs proposed by a research colleague, the land route scored -20 and the sea route scored -15 . So that evaluator apparently favored the less damaging sea route. She considered ecology to be the most important criterion and assessed the land route to have a significantly larger impact. The effect of alternative inputs by the same or other evaluators could be readily calculated.

\section{THE AMERICAN CASE: A PERMITTING PROCEDURE FOR OIL CONSTRUCTION PROJECTS}

\section{Setting}

The Russian case addresses how to help make a single, still-active decision. The American case addresses how to develop a reusable procedure for a class of future decisions.

A major recurring decision facing U.S. regulators with responsibility for Arctic development is whether to permit Alaskan oil construction projects, with or without restrictions. A number of parties, including industry and environmental groups, have been concerned that controversial decisions-such as whether to allow oil drilling in the Alaskan National Wildlife Refuge-are often subject to arbitrary and unpredictable pressures, for example, major shifts in the political climate. They have clamored for a standardized, "scientific" procedure that would not be susceptible to manipulation.

The U.S. Army Corps of Engineers (CoE) Alaska District has primary responsibility for evaluating permit applications, using the wetlands guidelines of the Clean Water Act. Typically one analyst within the Regulatory Branch makes a recommendation, based upon available evidence, through the Branch Chief to the District Engineer, who confers with various other federal and state agencies before rendering a decision.

\section{Research Task}

Our research team decided to first test the technical feasibility of our ideas on a past permitting incident: whether to permit British Petroleum (BP) to build a causeway to its Niakuk oil field in the Arctic Ocean. Though CoE personnel provided extensive input on specific aspects of the case, including the criteria that are used in deciding permits, we felt that the issue was still too controversial to show how their analysis might have been done. We chose instead to show the results $a$ s if the applicant were putting forward its argument based upon the categories and definitions of impacts that the CoE might use. We put together the evaluation described here entirely from secondary sources. BP, the actual applicant, had no input.

\section{Niakuk Background}

In the late 1980s, BP sought permission to develop the Niakuk oil field from an artificial island about $2 \mathrm{~km}$ offshore in the Beaufort Sea, using a gravel causeway to pipe the oil ashore. The Alaska District of $\mathrm{CoE}$ gave a conditional permit that did not allow for the construction of the proposed causeway, on the grounds that the proposal did not meet the 
TABLE 2. NDA hypothetical qualitative analysis of Niakuk (Alaska) permit application. Positive consequences are given in bold. An asterisk ("*”) indicates an unacceptable level of impact, and a dagger ("†") indicates that the option is economically impracticable on that criterion.

\begin{tabular}{|c|c|c|c|c|c|c|}
\hline Affected party & Type of consequence & $\begin{array}{l}\text { Causeway } \\
\text { impacts }\end{array}$ & $\begin{array}{l}\text { Slant drilling } \\
\text { impacts }\end{array}$ & $\begin{array}{l}\text { Interpretation of } \\
\text { very high impact }\end{array}$ & Unacceptable & Importance \\
\hline \multicolumn{7}{|c|}{ General public (environmental concerns) } \\
\hline & Fish populations & High* $^{*}$ & Very low & 10 years to restore & High & $\bullet$ \\
\hline & Animal populations & Very low & Very low & 10 years to restore & Low & $\bullet \bullet$ \\
\hline & Aquatic sites (wetlands) & Low & Low & Comparable to Everglades & High & $\bullet$ \\
\hline & Other fauna (endangered species) & Very low & Very low & $5 \%$ probability of extinction & 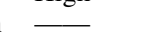 & $\bullet \bullet$ \\
\hline & Water quality & Very low & Medium* & 2 spills over project life & Low & $\bullet$ \\
\hline & Wilderness/ecology & High & Low & Comparable to Deadhorse & & $\bullet$ \\
\hline \multicolumn{7}{|l|}{ National interest } \\
\hline & Oil independence & Very low & Very low & $5 \%$ less oil imports & - & $\bullet \bullet$ \\
\hline State and local & Revenue (royalties) & Low & Very low & \$1B over life of field & 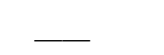 & $\bullet$ \\
\hline \multicolumn{7}{|l|}{ Local population } \\
\hline & Subsistence (waterfowl) & Very low & Very low & 1 major species out 1 year & - & $\bullet$ \\
\hline & Employment & Low & Low & 200 more permanent jobs & - & $\bullet$ \\
\hline & Economy & Very low & Very low & $20 \%$ improvement & - & $\diamond$ \\
\hline \multicolumn{7}{|l|}{ Industry } \\
\hline & Niakuk profitability & Medium & Very low $\dagger$ & $\$ 1 \mathrm{~B}$ earnings & Very low $\dagger$ & $\bullet \bullet$ \\
\hline & Other BP profitability & Very high & Low & $\$ 1 \mathrm{~B}$ earnings & & $\bullet \bullet$ \\
\hline & Other firms' profitability & High & Very Low & $\$ 1 \mathrm{~B}$ earnings & - & $\bullet \bullet$ \\
\hline
\end{tabular}

terms of an agreement between the oil companies and federal regulators to maintain fish habitat. A regulatory guideline [404(b)(1) of the Clean Water Act] says that, irrespective of other considerations, a permit has to be denied if a fish population would be adversely affected. The agreement among the companies and agencies had been to judge potential changes in fish populations on the basis of changes in habitat. Causeways were believed to affect the habitat of arctic cisco by changing coastal current patterns. The senior official judged the causeway to have overall social value; however, under existing regulatory procedures, regulators cannot trade off some negative environmental impacts against other positive values.

The Alaska District also issued a general directive favoring alternative means of accessing offshore oil, such as slant drilling from the shore, over causeways. This directive raised the case from a single decision to a precedent, with implications for further development. BP had argued against slant drilling, on the grounds that it was more costly than causeway construction-costly enough to prevent development of the field.

The federal government put pressure on CoE headquarters in Washington to rescind these decisions, pending additional data. CoE acquiesced. A Congressional committee in turn challenged this reversal, claiming improper industrial influence. BP ultimately dropped the causeway in favor of slant drilling (which, in fact, proved quite profitable, as slant drilling allows greater recovery).

\section{Research Effort}

We sought an aid that would help make the regulator's decision process sounder, smoother, more defensible, and less wasteful of national resources. The research team met with the regulator (Alaska District of $\mathrm{CoE}$ ) four years after the events described, to develop an NDA-oriented aid that could have been used to support the initial local permitting application. The analysis was intended to reflect faithfully whatever knowledge and thinking had been available to BP at the time (without attempting to improve them). Its contribution was to find the best way to communicate the likely consequences of each of three permitting options (no oil field, oil field with a causeway, and oil field without a causeway) and to determine if those consequences were acceptable.

We considered three alternative formats: qualitative, graphic, and numerical (Table 2, Figs. 3 and 4). In each case we took into account all consequences-economic, environmental, strategic, etc.-no matter how intangible. Importance and impact judgements were separately defined and independently evaluated. We considered both the existing decision regime, in which thresholds eliminated an option, and an alternative one, in which decision makers could consider that the good aspects of an option might compensate for its bad aspects.

\section{Qualitative Representation}

The first two columns of Table 2 list consequences, grouped by who is mainly affected. Consequences in bold indicate positive impacts. Columns 3 and 4 predict consequences for each option. They show that some impacts are more acceptable with slant drilling (very low impact on fish population) and some are better with the causeway (water quality). Column 5 clarifies the meaning of the levels of impact by defining "very high impact." In the case of "fish population," for example, it is interpreted as "10 years to restore" (or equivalent harm). Column 6 indicates what is unacceptable according to statute. For example, if statutory limits were the 


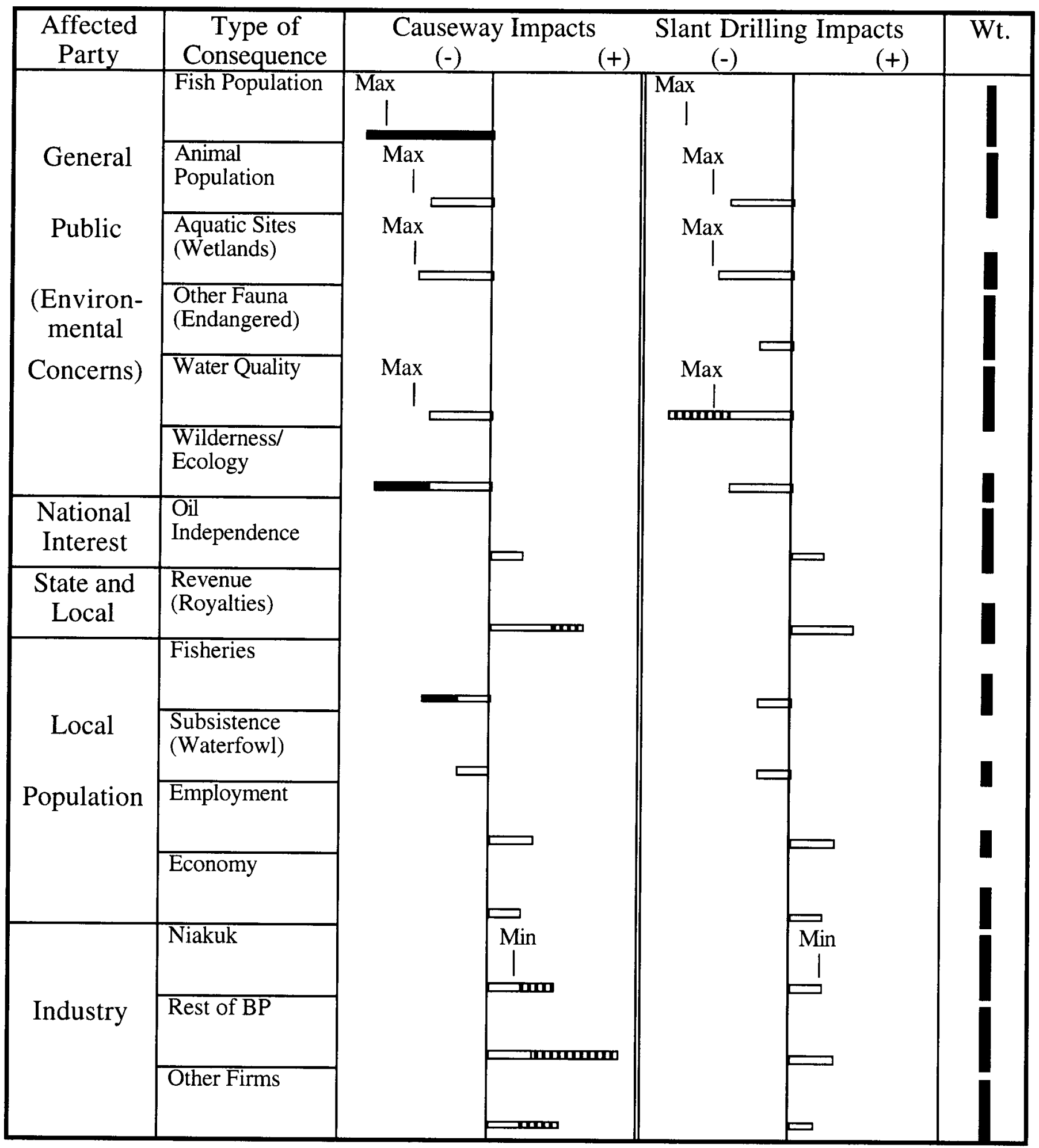

FIG. 3. NDA hypothetical graphic analysis of Niakuk (Alaska) permit application, using bar graphs. Vertical lines, labelled "Max" or "Min" indicate an unacceptable impact. The black portion of the horizontal bars indicates impacts favoring slant drilling, while the cross-hatching indicates those favoring the causeway. In this graphical presentation, impact and importance are separate. The NDA analysis maintains separate rows for all of the criteria that must go into the decision.

controlling principle, the impact on fish population alone would make the causeway unacceptable.

On the other hand if, contrary to literal interpretation of the current regulations, compensation among impacts were allowed, the preferred option would depend on which impact is more important, as shown in the last column. In practice, a regulator may stretch interpretation of thresholds to take trade-offs into account. This qualitative format may help regulators make the necessary evaluation informally. 


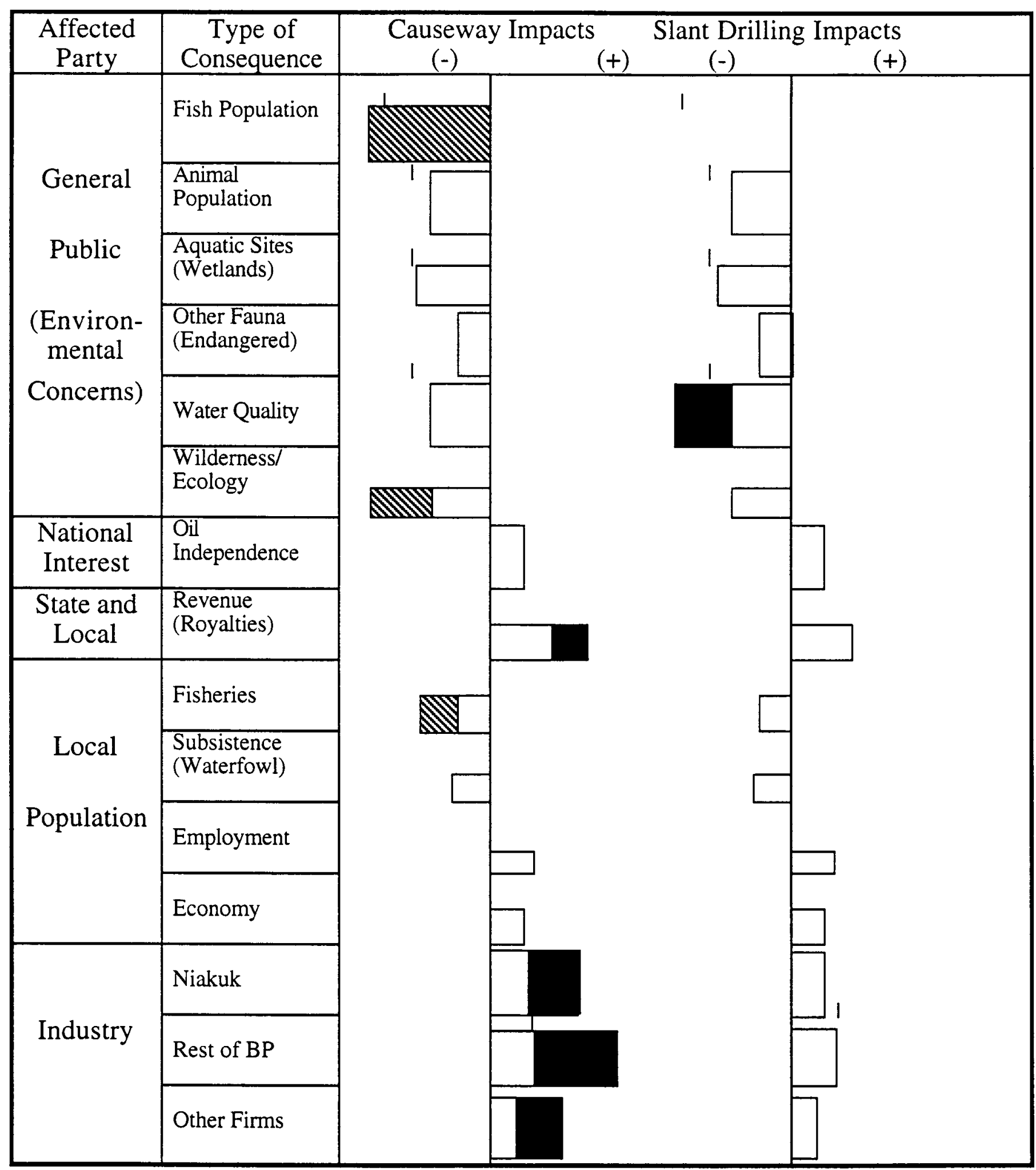

\section{NET DIFFERENCES \\ Favor CW \\ Favor SD

FIG. 4. NDA hypothetical graphic analysis of Niakuk (Alaska) permit application, using boxes. Impact and importance are combined into boxes. Width represents impact and height importance. The small vertical line indicates an unacceptable or impractical impact. The black portion of the boxes indicates that slant drilling is favored. The cross-hatching indicates that the causeway is favored. An observer or decision maker can readily compare areas and see the similarity between a small impact on a criterion of great importance and a large impact on an area of less importance. The two bars at the bottom graphically display the sum of the net differences in areas. 


\section{Graphic Format}

Figure 3 expresses essentially all the same judgements as Table 2, but quantitatively, in a graphic format, and more precisely. The level of impact, positive or negative, of each option on each consequence, is represented by a horizontal bar. For example, in "fish population," "high" impact is represented by a bar that is long, but not as long as a bar for the maximum or "very high" impact. (Equivalently, that impact could be given a numerical score on a scale from 0 100 , correspondingly defined). The small vertical line above the bar labelled "Max" indicates the maximum acceptable impact, noted as "high" for "fish population" impact of "causeway" in Table 2, but now more precisely represented as a little less than the width of the box-and therefore again characterized as "unacceptable." The bar in the final column represents importance weight, corresponding to the number of stars in the last column of Table 2. The long bar for "fish population" corresponds to three stars in Table 2. However, it is less high than the bar for "animal population," which also got three stars in Table 2, reflecting the greater precision of Figure 3.

In Figure 4, two dimensions of impact and importance are combined as the area of the box (that is, as the product of impact and importance). This area indicates the net effect of an option's consequence on that criterion. Thus, the causeway has a significant effect via fish population (as shown by a large box) because the size of the impact is large and the importance is substantial (but not as high as some others.)

By comparing the total area of boxes favoring causeway (shown black) with those favoring slant drilling (crosshatched), we have an indication of which option is preferred. Since the causeway area is clearly much larger than the slant drilling area, the causeway option should be accepted, according to this example. One can see by eye that the greater area favoring causeway is due largely to the high impact and high importance attached to three measures of industry profitability. This evaluation is what one might expect from an oil company applicant. The regulators do not have to accept these importance weights, of course; they can substitute their own assessments when coming to a decision.

Although numbers can communicate the same assessments, these graphic representations can be better for communication. Whereas the numbers themselves may be difficult for a lay person to understand, the relative shape and size of the different boxes can convey the important differences. Finally, the boxes may avoid conveying a false precision. Whereas the decision maker may not intend to imply a precision of, say, 35 (as opposed to 34 or 36), the box diagram does not necessarily convey anything but a fairly rough estimate.

\section{Handling Uncertainty}

This graphical format does not capture uncertainty (nor does the qualitative format). A single quantity represents each impact prediction, regardless of how suspect the assessment may be. Although uncertainty may be important for a risk-averse decision maker, if the causeway impacts are plausibly no more uncertain than for slant drilling, the causeway would still be preferred. The decision maker can always discount the value of very uncertain impacts by making single-number estimates conservative. However, it may be helpful to register the uncertainty explicitly, to make clear to any observer where the "net" impact estimate came from. Though we could not do it here, one could handle this by shading the boxes darker for more certain estimates, or simply by adding the words "low," "medium," or "high" in a column for uncertainty.

A purely numerical presentation can incorporate estimates of uncertainty algebraically. If each impact is assigned a margin of error, e.g., $10 \pm 30$, an overall margin of error for the net value of each option can be approximated by a formula.

Note that "uncertainty" as used here refers to both the doubt of the decision maker toward the given estimate and the amount of possible variation in the particular criteria. On the whole, however, the decision makers were most concerned about the precision of a given estimate.

\section{Live Decision: Badami}

BP recently proposed development of another new field on the North Slope, called Badami. The American team met with a regulator and used the decision aid to analyze two options under the then active permit request. (BP has subsequently withdrawn this particular request and has provided a new one). In the plan to develop Badami, BP proposed several innovations that would have reduced environmental impact. These include a small footprint for the drilling pad that takes advantage of slant drilling, transportation of materials to the site during winter to eliminate the need for a road, and chilled rather than heated oil in the pipeline. One reading of this effort suggests that in addition to making the Badami field more harmonious with the landscape, the approach could set a precedent for development in ANWR.

The regulator identified the pipeline construction plan as the key issue in deciding on the permit. The pipeline would have connected the field with the Trans-Alaska Pipeline System. The proposer, BP, wanted to bury the pipeline completely, even at river crossings. Traditionally, pipelines cross rivers on bridges, so completely burying the pipeline would have been new. Buried pipelines cause a problem by dissipating heat into the surrounding permafrost, causing the development of thermokarsts around the pipe. For this reason, pipelines are generally kept aboveground in permafrost areas. BP proposed new technology to overcome this problem.

At river crossings, the pipeline would be put below ice scour depth. Sagbends, dips in the pipeline on either side of the river crossing, would be set back from the river bank far enough to allow a gradual transition to a deeper substream level and avoid the effects from bank erosion. The pipeline would require four major and multiple minor creek crossings. The regulator felt that consideration should be concentrated 
TABLE 3. NDA hypothetical numerical analysis of Badami (Alaska) permit decision.

\begin{tabular}{|c|c|c|c|c|c|c|c|c|}
\hline \multirow[b]{2}{*}{ Consequence, impact on } & \multirow[b]{2}{*}{ Importance $^{1}$} & \multicolumn{3}{|c|}{ Completely Buried } & \multicolumn{3}{|c|}{ Buried Except at Crossings } & \multirow{2}{*}{$\begin{array}{c}\text { Advantage } \\
\text { Buried }\end{array}$} \\
\hline & & Impact & Uncertainty $^{2}$ & Contribution $^{3}$ & Impact & Uncertainty $^{2}$ & Contribution $^{3}$ & \\
\hline Special aquatic sites impact & -0.3 & 15 & 0.15 & -4.5 & 7 & 0.15 & -2.1 & -2.4 \\
\hline Anadromous fish - Sea & -1 & 5 & 0.15 & -5 & 5 & 0.15 & -5 & 0 \\
\hline Anadromous fish - River & -1 & 5 & 0.15 & -5 & 5 & 0.15 & -5 & 0 \\
\hline Anadromous fish - positive effect & 1 & 50 & 0.15 & 50 & 45 & 0.15 & 45 & 5 \\
\hline Other fish/aquatics & -0.3 & 5 & 0.15 & -1.5 & 5 & 0.15 & -1.5 & 0 \\
\hline Wildlife & -0.3 & 5 & 0.15 & -1.5 & 10 & 0.15 & -3 & 1.5 \\
\hline Marine mammals & -0.3 & 5 & 0.15 & -1.5 & 5 & 0.15 & -1.5 & 0 \\
\hline Other endangered species & -1 & 5 & 0.15 & -5 & 5 & 0.15 & -5 & 0 \\
\hline Ecosystem & -1 & 5 & 0.15 & -5 & 5 & 0.15 & -5 & 0 \\
\hline Permafrost integrity & -1 & 15 & 0.8 & -15 & 5 & 0.15 & -5 & -10 \\
\hline Physical properties & -0.7 & 5 & 0.15 & -3.5 & 5 & 0.15 & -3.5 & 0 \\
\hline Circulation & -0.15 & 5 & 0.15 & -0.75 & 5 & 0.15 & -0.75 & 0 \\
\hline Erosion, accretion & -0.5 & 10 & 0.5 & -5 & 5 & 0.15 & -2.5 & -2.5 \\
\hline Turbidity & -0.1 & 5 & 0.15 & -0.5 & 5 & 0.15 & -0.5 & 0 \\
\hline Ice dynamics & -0.5 & 5 & 0.15 & -2.5 & 5 & 0.15 & -2.5 & 0 \\
\hline Oil pollution & -0.7 & 5 & 0.3 & -3.5 & 5 & 0.15 & -3.5 & 0 \\
\hline Other water quality & -0.15 & 5 & 0.15 & -0.75 & 5 & 0.15 & -0.75 & 0 \\
\hline Soil quality & -0.5 & 5 & 0.15 & -2.5 & 5 & 0.15 & -2.5 & 0 \\
\hline Fisheries & -0.1 & 5 & 0.15 & -0.5 & 5 & 0.15 & -0.5 & 0 \\
\hline Energy & 1 & 15 & 0.15 & 15 & 15 & 0.15 & 15 & 0 \\
\hline Pro-wilderness sentiment & -1 & 40 & 0.15 & -40 & 40 & 0.15 & -40 & 0 \\
\hline Native way of life & -0.5 & 5 & 0.15 & -2.5 & 5 & 0.15 & -2.5 & 0 \\
\hline State/borough oil finances & 0.8 & 40 & 0.15 & 32 & 40 & 0.15 & 32 & 0 \\
\hline Construction business and employmen & 0.8 & 30 & 0.15 & 24 & 30 & 0.15 & 24 & 0 \\
\hline Operations business and employment & 0.8 & 10 & 0.15 & 8 & 10 & 0.15 & 8 & 0 \\
\hline Other state/borough finances & 0.2 & 10 & 0.15 & 2 & 5 & 0.15 & 1 & 1 \\
\hline Other & -0.2 & 5 & 0.15 & -1 & 15 & 0.15 & -3 & 2 \\
\hline Badami income for BP & 0.3 & 20 & 0.15 & 6 & 10 & 0.15 & 3 & 3 \\
\hline Precedent for industry & 0.3 & 50 & 0.15 & 15 & 10 & 0.15 & 3 & 12 \\
\hline Meeting applicant's purpose & 0.7 & 100 & 0 & 70 & 70 & 0.15 & 49 & 21 \\
\hline Precedent for environmentalists & -0.3 & 35 & 0.15 & -10.5 & 10 & 0.15 & -3 & -7.5 \\
\hline Totals & & & 20.89 & 104.5 & & 16.75 & 81.4 & 23.1 \\
\hline
\end{tabular}

${ }^{1}$ A negative number indicates the importance of a negative impact.

${ }^{2}$ Total uncertainty equals the square root of the sum of the estimated uncertainties for each criterion.

${ }^{3}$ Contribution equals importance times impact.

on this issue. Opponents to the permit had also highlighted the innovative pipeline design, though the permit itself was relatively uncontroversial.

The research team used essentially the same format analysis as with the Niakuk case. The difference was in the arrangement of effects. The final analysis was done by the regulator without the American team present, three months after the original meeting.

Since the permit decision is still active, and BP's application has changed since the analysis, we cannot display the resulting table. Table 3 does, however, have a similar structure and outcome to what the regulator gave. The research team's analysis also included hypothetical judgements of uncertainty to show how these might look. The completely buried pipeline is displayed as being more in the public interest than the pipeline raised over stream crossings, with an evaluation of $104.5 \pm 20.89$ versus $81.4 \pm 16.75$. In the researchers' rendering of the table, the completely buried option had positive effects from gravel pits in creating improved habitat for anadromous fish, in the precedent effect for the industry, and in meeting the applicant's purpose. The major negative difference was in the possible impact on permafrost integrity. The table suggests that the completely buried option may have a greater and more uncertain effect on permafrost integrity. This uncertainty reflected the relative newness of the approach. Other major negatives might be possible erosion and setting what environmentalists might consider a bad precedent.

\section{CDA Analysis of Niakuk}

Table 4 shows a qualitative analysis of the Niakuk decision carried out by the Russian research team. The analysis, which shows eight variables, was done from the perspective of a regulator. It adds a third alternative to the two considered in the NDA analysis: a subsea pipeline below the ice scour level of the ocean's floor. Of the criteria, one is considered to have no difference among the options: social consequences. Qualitative analysis does not attempt to draw out every single point of difference in detail. It seeks only the "broad brush strokes."

Because of the threshold for anadromous fish, incorporated into the impact on the environment, the causeway was considered unacceptable and was eliminated as an option. The question then arose, was there another option that could be used as a better alternative to slant drilling? The major 
TABLE 4. CDA hypothetical qualitative analysis of Niakuk (Alaska) permitting decision. The italics indicate the major differences among the options.

\begin{tabular}{|c|c|c|c|c|}
\hline \multirow[b]{2}{*}{ Groups $^{1}$} & \multirow[b]{2}{*}{ Criteria } & \multicolumn{3}{|c|}{ Evaluation of Alternatives } \\
\hline & & Causeway & Slant Drilling & Subsea Pipeline \\
\hline $\mathrm{ABC}$ & Impact on the environment & Unacceptable $^{2}$ & Acceptable & Acceptable \\
\hline $\mathrm{AB}$ & Damage to wilderness & Big & No & Small \\
\hline $\mathrm{AB}$ & Social consequences & & - Equally negligible - & \\
\hline $\mathrm{ABC}$ & Quantity of oil & Basic volume & Less & Equal to basic \\
\hline $\mathrm{C}$ & Cost of construction & Basic cost & $\$ 14-30$ million more $(5-10 \%)$ & $\$ 37$ million more $(10-15 \%)$ \\
\hline A & Oil independence & Estimated input & Less & Equal \\
\hline $\mathrm{ABC}$ & Uncertain factors $^{3}$ & A few & Very many & Many \\
\hline $\mathrm{ABC}$ & Reliability of pipeline ${ }^{4}$ & Normal & Normal & Less \\
\hline
\end{tabular}

${ }^{1}$ Active groups: $\mathrm{A}=$ public; $\mathrm{B}=$ local authorities; $\mathrm{C}=$ oil companies.

2 The available knowledge confirms a real danger to the environment.

${ }^{3}$ A lack of knowledge for effective realization of the alternatives.

${ }^{4}$ Risk of accident: detecting and eliminating.

differences between the two remaining options were found in the cost of construction, the number of uncertain factors, and the reliability of the pipeline. The buried pipeline had disadvantages in its extra cost and reduced reliability. Slant drilling was disadvantageous in its many uncertain factors, which might have blocked its effective realization.

At this point, the qualitative analysis would have needed to know whether the disadvantages of the buried pipeline could have been made at least equal to those of slant drilling. The buried pipeline, according to the analysis, had a number of advantages over the alternative. Reducing the cost of construction or increasing the reliability to the level of slant drilling might have made a buried pipeline a better alternative. In any case, the analysis can aid the decision maker by showing where the major differences lie.

\section{DISCUSSION: COMPARING APPROACHES}

Because actual decision cases are used, an experimental situation cannot be created in which "treated" and "untreated" parallel cases can be compared. The analyst or the decision maker can only judge that the decision made with the help of the decision aids was better than it might have been otherwise. Does this limitation render a third-party evaluation of decision aids completely impossible? Not entirely. Secondary criteria can suggest whether a particular technique is better to particular ends. In the case of the Arctic, these secondary evaluation criteria can address the characteristic needs of decision makers in this region of the globe.

\section{Decision Issues Important to the Arctic}

The two methods studied here suggest at least nine decision issues: complexity reduction, consideration of alternatives, personal clarification for the decision maker, finding compromises, favoring of interests, communication, ability to reuse the method, ease of use, and incorporation of uncertainty (Table 5).
Most of these secondary criteria, though important to the Arctic, are not Arctic-specific: they would be important for public environmental decisions elsewhere in the world. Their importance to the Arctic is a matter of degree rather than kind. For example, complexity reduction addresses a problem that is found throughout environmental decision making: how to make comparisons across several different criteria that use different measures and incorporate different levels of certainty (e.g., Committee on the Human Dimensions of Global Change, 1994:18). However, decisions about Arctic resources tend to be more public, because they are more likely to be on public land and involve more groups with divergent interests. Personal clarification and communication are also important to any public policy decision. Communication may be more difficult for Arctic issues because the topics and their importance may be farther from the knowledge of most people, even those involved in government decision making. The applicability of a decision tool to a class of decisions, and the attendant ability to reuse it, will mean that the procedure can become part of a management regime and provide a clear and consistent approach to those decisions. A better understanding on the part of the public is more likely to emerge. Consideration of alternatives may be more important in the Arctic because the environment may benefit from or require new technology or approaches. An important corollary to the consideration of alternatives is whether the methods aid the search for compromises among groups. Arctic decisions typically involve different interest groups within the same level of government, among the levels of government, and within the larger public. By extension, does one approach or the other favor particular interests? This issue also raises ease of use as a question, since more technical approaches may favor better-educated or more experienced groups. The incorporation of uncertainty is perhaps the most Arcticspecific issue, because the Arctic environment is characterized by large seasonal and interannual variation; decision makers have a poorer information base, as less research has been conducted; and oil companies must deal with wellhead price swings brought about by the large fixed costs for 
TABLE 5. Comparison of CDA and NDA on aspects of decision making important to Arctic resource decisions.

\begin{tabular}{|c|c|c|c|}
\hline Criteria & Categorical & Numerical & Importance to Arctic \\
\hline Dealing with Complexity & $\begin{array}{l}\text { - Eliminates criteria where no } \\
\text { differences exist. } \\
\text { - Seeks to reduce some criteria to dollar } \\
\text { amounts. } \\
\text { - Alters the negative features of one } \\
\text { alternative to create a new alternative. } \\
\text { - Creates "psychologically valid" } \\
\text { binary choices. }\end{array}$ & $\begin{array}{l}\text { - Seeks numerical value for each } \\
\text { criterion on importance and impact } \\
\text { scales and combination of two. } \\
\text { - Allows direct comparison of } \\
\text { alternatives and criteria through } \\
\text { scores, and suggests a decision. }\end{array}$ & $\begin{array}{l}\text { - Public ownership of land and } \\
\text { environmental characteristics can } \\
\text { create several interacting issues. } \\
\text { - Interest groups can purposely create } \\
\text { complexity to prolong debate or shift } \\
\text { costs. }\end{array}$ \\
\hline Considering Alternatives & - Forces consideration of alternatives. & $\begin{array}{l}\text { - Does not require consideration of } \\
\text { alternatives, but can suggest them. } \\
\text { - Can consider compensating actions } \\
\text { that are not part of an alternative. }\end{array}$ & $\begin{array}{l}\text { - Because most projects are unique, } \\
\text { alternatives are not well known. }\end{array}$ \\
\hline Clarification for the Decision Maker & $\begin{array}{l}\text { - Focuses on essential differences. } \\
\text { - Forces a decision maker to consider } \\
\text { alternatives. } \\
\text { - Because the method does not provide } \\
\text { a final decision, decision makers may } \\
\text { not necessarily see the implication of } \\
\text { their evaluation of criteria. }\end{array}$ & $\begin{array}{l}\text { - Can point out whether analysis of } \\
\text { criteria is consistent with "gut" choice } \\
\text { between alternatives. }\end{array}$ & $\begin{array}{l}\text { - The public nature of decisions and } \\
\text { the possiblity of litigation require the } \\
\text { decision maker to reach a justifiable } \\
\text { decision. }\end{array}$ \\
\hline Finding Compromises & $\begin{array}{l}\text { - Searches for alternative options, } \\
\text { including possible compromises. }\end{array}$ & $\begin{array}{l}\text { Does not include compromise as an } \\
\text { integral part of method, but does allow } \\
\text { for trade-offs between criteria and, } \\
\text { thereby, stakeholders. }\end{array}$ & $\begin{array}{l}\text { - Multiple stakeholders participate in } \\
\text { public decisions. }\end{array}$ \\
\hline Favoring Stakeholder Groups & $\begin{array}{l}\text { - May encourage wider range of } \\
\text { stakeholder participation. }\end{array}$ & $\begin{array}{l}\text { - Requires numeracy, which may } \\
\text { disfavor less educated groups. } \\
\text { - Harder to integrate rights-based } \\
\text { approach. }\end{array}$ & $\begin{array}{l}\text { - Stakeholder groups may differ widely } \\
\text { in education, power, and rights. }\end{array}$ \\
\hline Communication & $\begin{array}{l}\text { - Provides clear and quick description } \\
\text { of the decision problem. } \\
\text { - Focuses discussions by reducing } \\
\text { unnecessary complexity. }\end{array}$ & $\begin{array}{l}\text { - Shows detail about how decision } \\
\text { maker weighed different criteria and } \\
\text { their impact. } \\
\text { - Can discuss numbers and alter them. } \\
\text { - Gives permit applicant a template with } \\
\text { which to work. }\end{array}$ & $\begin{array}{l}\text { - Public has major involvement in } \\
\text { decisions. } \\
\text { - Public has low knowledge of } \\
\text { background and issues. } \\
\text { - Obscuring issues is a potential } \\
\text { stakeholder tactic. }\end{array}$ \\
\hline Ability to Reuse & $\begin{array}{l}\text { - Requires a new approach to analysis } \\
\text { for each decision problem. }\end{array}$ & $\begin{array}{l}\text { - Applies to a class of permitting } \\
\text { decisions. } \\
\text { - Can be used as template for permit } \\
\text { applications. }\end{array}$ & $\begin{array}{l}\text { - Tools can provide a general approach } \\
\text { to unique Arctic issues. } \\
\text { - Tools can reduce the cost of ad } \\
\text { hoc approaches to environmental } \\
\text { decisions. }\end{array}$ \\
\hline Ease of Use & - Is easily understandable. & $\begin{array}{l}\text { - Requires numeracy. } \\
\text { May require training for decision } \\
\text { maker. }\end{array}$ & $\begin{array}{l}\text { - At some decision-making levels, } \\
\text { educational attainment is low. }\end{array}$ \\
\hline Incorporating Uncertainty & $\begin{array}{l}\text { - Considers uncertainty as one criterion. } \\
\text { - May transform uncertainty to the } \\
\text { dollar cost of removing it. }\end{array}$ & $\begin{array}{l}\text { - Asks decision maker for estimate of } \\
\text { uncertainty. } \\
\text { - Provides overall uncertainty for each } \\
\text { alternative. }\end{array}$ & $\begin{array}{l}\text { - The Arctic environment is highly } \\
\text { variable. } \\
\text { - Well-head prices are volatile. } \\
\text { - Unexpected costs may arise. }\end{array}$ \\
\hline
\end{tabular}

transportation. Finally, because construction and operation often use new techniques, it is difficult to figure accurately the cost of any project. Prior experience may not be available as a guide. Thus, uncertainty is a key issue.

\section{Complexity Reduction}

While decisions about oil and gas development in the Arctic are often portrayed as a battle between development and the environment, the skirmishes take place in several arenas. Because development takes place on public land in both Russia and the United States, several interest groups are usually involved, each of which may have a distinct concern or stake - or even more than one. Development, primarily a consideration of economic interests, may concern the company carrying out the activity, the local or regional government, or the federal government. All may have an interest in seeing the development take place, but with enough differences among them, e.g., taxes versus profits, that they cannot be considered to have the same interest. Complexity can arise from defining those differences as aspects of the same national interest. Similarly, the environment is not a single entity. Development may improve some aspects of the environment, while negatively affecting others. Finally, within 
the United States, the battle often takes place in a legal forum. Delay is a tactic, and creating complexity may be a way to increase delay.

The qualitative approach eliminates much of the complexity by reducing the question to the bare essential of differences. The quantitative method does not reduce the complexity per se, but it brings to bear a common denominator. A chief issue between the two methods is whether the numbers created under the quantitative approach are "real": do they truly reflect psychological states in which numerical intervals are equidistant and values placed on different impacts follow a common scale allowing comparison? Both methods, each in their way, reduce complexity and thus achieve a valuable public goal. This reduction allows both decision makers and the general public who have no firsthand knowledge of the Arctic to understand what the essential issues are.

\section{Consideration of Alternatives}

The two methods differ considerably in whether they force consideration of alternatives. The qualitative approach engenders a search for another alternative that has not previously been considered. This alternative can be a new variant developed by altering the negative features of one approach, as seen in the Yamal case, or it can be an entirely new method for solving the problem, as in the Niakuk case. The quantitative approach, though it can consider other alternatives, does not use their creation as a tool in the analysis, nor does it force consideration of alternatives. Someone looking for alternatives could use NDA to locate the largest disadvantages of the existing options and try to develop another option based on those observations.

The forcing of alternatives can be important in the Arctic: the unique conditions can call for new solutions to engineering problems. One example may be the development of freonfilled pipeline supports in Alaska. Environmentalists raised the concern that the originally proposed buried pipeline, or even the supports of a raised pipeline, would cause thermokarsts. The development of the supports solved this problem, and probably saved the pipeline company considerable repair costs. The forcing of an alternative benefited both the environment and the oil industry.

The quantitative approach, on the other hand, allows the consideration of compensating actions. Thus, the analysis may point out that a positive impact outweighs a negative one in another category. The qualitative approach has no way of considering this trade-off, because it does not attempt to provide the means to cross-compare criteria unless comparisons can be made in money equivalents. For instance, an applicant could propose to replace wetland in the project area by creating wetland of equal or greater value in another area. Compensating actions may be less feasible in the Arctic environment, because slower biological processes would lengthen the time needed to create, say, a new wetland or other biophysical feature.

\section{Clarification}

Both methods clarify the decisions. The decision makers with whom we worked in both the United States and Russia had a similar experience: after the first iteration on the model, and after some time to think, they universally revised their analyses to reflect what they thought was an accurate model. In the quantitative approach, the clarification came when the consequences of the modeling were clear. The decision makers saw a result that was counter to what they thought was the correct decision. That is, thinking about the individual factors influencing the decision did not add up to the decision that a decision maker thought correct. The decision maker then had the option of either rethinking the individual factors or rethinking the decision. By forcing consistency, the decision analysis techniques can help us avoid many of the decision-making pathologies that plague ad hoc decisions.

The use of numbers in the analysis would add to the clarity of a decision when scales are carefully constructed. A numerical approach also clarifies by not reducing a complex question such as the environment to a single factor: it maintains and deals with the multiple elements that make up any key area of a decision. However, the quantitative approach is not likely to lead to clarification, or communication, if the people using it, or those to whom it is directed, are not numerically sophisticated. The approach worked well with decision makers in the Corps of Engineers because they were trained scientists, but what about people in the small villages of Alaska? No a priori assumptions can be made one way or the other.

The non-numerical CDA analysis requires the decisionmaking process to identify and deal with the essential differences between different options. That is, clarity is achieved by eliminating factors for which there is no real difference or which are not important to the decision maker, rather than transforming them into numbers as in NDA.

\section{Finding Compromises}

NDA deals with single decision makers and their choices among an existing group of alternatives. As noted under the consideration of alternatives, it is possible to develop new options from the old options, but they are not part of the analysis. NDA does allow clearer trade-offs. CDA, in creating a new option when noncomparability exists, allows for the consideration of different interests and can try to create a compromise option based on an analysis of those interests. Aiding compromise reduces the cost of any decision.

\section{Favoring Interests}

NDA could favor certain interest groups over others. First, NDA requires greater numeracy, at least on the part of the decision maker. This problem might be overcome with the development of graphical prompting techniques. These techniques would not ask for numerical evaluations, but rather 
whether a series of boxes captures a decision maker's thinking on a decision.

However, a second problem would be more difficult to overcome. The quantitative approach is less able to deal with a "rights-based" approach to a particular decision. Under a rights-based approach, a group would not be willing to see its interests traded off against others because those interests are based on a legal right. Small groups within larger societies, such as Alaska Natives, typically emphasize this approach because they know that they will not necessarily win a majority decision. NDA has difficulty dealing with such thresholds, as it must add another factor to the analysis beyond importance, impact, and uncertainty. CDA can deal with it more easily. Taken together, these problems mean that NDA may disfavor smaller groups with lower numerical skills who must argue from a position of rights.

\section{Communication}

Both methods may be considered improvements over the often confounded discussions surrounding oil and gas development in the Arctic. Simply achieving greater clarity and reducing complexity do, to some extent, provide improved communication. Decisions are more transparent. The NDA approach can present its findings in more graphically interesting forms because of its numerical base. The research did not specifically attempt to measure improvements in communication, but other regulators who work with the CoE indicated that the analyses were improvements.

\section{Ability to Reuse}

As the American permitting case showed, the NDA approach can be applied to a class of decisions. The American researchers' tentative conclusion was that some variant of the NDA approach would be useful to regulators as a required format for industry-submitted construction applications or as a format for regulators to follow in making and explaining their own permitting decisions. (This conclusion needs to be tested in the context of a regulatory regime, but such testing was outside the scope of this study.) Because a chief characteristic of the CDA approach is that it reduces the number of criteria considered, it is less generalizable. That is, it must approach each decision anew and adapt its analysis accordingly.

\section{Ease of Use}

The CDA approach is easier to use because it employs natural language. The NDA required some learning on the part of the decision makers. Setting the scale (the meaning of the "100" impact) took considerable discussion, and making a judgement along that scale did not come naturally. These difficulties were encountered with decision makers who had a scientific background and were comfortable with numbers. One might well ask whether the difficulties might be even greater for people without this kind of background. With the rural villages of Alaska becoming more involved in important decision making, the analysis method used should be accessible to people less experienced with numbers. Thus, CDA may be most appropriate where a decision analyst does not have much time to work with the decision maker. NDA may be easier to work with as the length of time available increases.

\section{Uncertainty}

The approaches deal with uncertainty in very different ways. The CDA approach, in the Yamal case, looks at the cost of reducing uncertainty. That is, the qualitative approach translates uncertainty into a monetary figure. Even if decision makers decide not to pay that cost, it is not an unknown. A public debate can be pursued in which the value of uncertainty carries a concrete figure.

The NDA approach may attempt to estimate the amount of uncertainty. Here again the decision maker has to be able to think in quantitative terms to provide an estimate. The payoff is that the analysis can derive a single estimate of uncertainty to go with the single estimate of utility. Again, the uncertainty can be graphically presented. The public debate entrained by this treatment of uncertainty would cover the estimates given by the decision maker.

In both cases, the response might be to spend money on research to reduce the uncertainty. Under the CDA approach, a permit applicant or a decision maker will have a clear idea as to the opportunity cost of not doing the research. That is, the analysis can suggest that further research might be justified by cost reduction from not having to provide an engineering solution to the problem. If, for instance, a model could be developed to predict accurately the entrance of icebergs into Baydaratskaya Bay, with the result that a ship need be stationed in the bay only during those times, the value of the research and the maximum suggested cost would be equal to the cost reduction from periodic rather than constant monitoring. The NDA approach does not give a dollar cost in the same way. It does point out more clearly, however, where the issues lie. As uncertainty makes an impact less desirable, an incentive exists to improve the precision of figures given.

\section{Institutional Acceptance of the Methodologies}

Initially, CoE decision makers appeared more comfortable with CDA, but they became more accepting of NDA as they used it. The CoE has not taken the step of using either method as a formal part of its permit application procedure. This step would probably require review at levels higher than the Alaska District Office Regulatory Branch.

Two instances of nonacceptance did arise, however, during the course of research. In both cases, the people failed to understand that the analysis techniques were not intended as objective analyses which would support the decision makers' own knowledge and thinking. Nor do the methods magically transform the decision makers' decision into something more robust than it already is. The methods do make 
subjective decisions more understandable to others and, in this respect, make the decisions more public, if not more objective.

\section{CONCLUSIONS}

Decision analysis methods differ in how they address Arctic oil and gas issues. These differences suggest that such methods can improve oil and gas decision making, rendering it clearer both to the public and to the decision maker. Arctic resource decisions are public and do need better public understanding. These methods therefore suggest that improved decision analytic methods are an important research objective.

Arguably, Arctic resource decisions are among the most thorny environmental issues because of their complexity and uncertainty. Methods developed for the Arctic may therefore serve well elsewhere. They may also be applied to several areas that are not strictly environmental issues, such as allocating basic scientific research funds. Arctic oil and gas decision makers must think not just about their decisions, but about how their decision making might be clarified and communicated.

\section{ACKNOWLEDGEMENTS}

The United States National Science Foundation's Arctic Social Science Program supported this research. The authors wish to thank Oran Young, Anthony Starfield, and three anonymous reviewers for their comments on earlier drafts. Nat Case of Hedburg Maps and Keith Chamberlin of FLEK, Inc. aided with the figures.

\section{REFERENCES}

ANDRE'EVA, Y., LARICHEV, O.I., FLANDERS, N.E., and BROWN, R.V. 1995. Complexity and uncertainty in Arctic resource decisions: The example of the Yamal pipeline. Polar Geography and Geology 19:22-35.

BERKELEY, D., HUMPHREYS, P., LARICHEV, O., and MOSHKOVICH, H. 1991. Aiding strategic decision making: Derivation and development of ASTRIDA. In: Vecsenyi, Y., and Sol, H., eds. Environment for supporting decision processes. Amsterdam: North Holland. 59-62.

BROWN, R.V. 1987. Decision analytic tools in government. In: Levitan, K.B., ed. Government infostructures. Westport, Connecticut: Greenwood Press. 69-83.

COMMITTEE ON THE HUMAN DIMENSIONS OF GLOBAL CHANGE, NATIONAL RESEARCHCOUNCIL. 1994. Science priorities for the human dimensions of global change. Washington, D.C.: National Academy Press.

EREV, I., and COHEN, B. 1990. Verbal versus numerical probabilities: Efficiency, biases, and the preference paradox. Journal of Organizational Behavior and Human Decision Processes 45:1-18.
EXPERT COMMISSION. 1989. The final assessment on the feasibility study of Yamal-Baydaratskaya Bay system pipeline construction, Expert Commission conclusions. Moscow: USSR State Committee on Natural Environment and Resources Management.

FLANDERS, N.E. 1993. International markets, national security and local control: Oil in Arctic Alaska. In: Heininen, L., and Katermaa, T., eds. Regionalism in the North. Rovaniemi, Finland: University of Lapland. Arctic Centre Reports No. 8. 9-18.

GUSTAFSON, T. 1989. Crisis amid plenty: The politics of Soviet energy under Brezhnev and Gorbachev. Princeton: Princeton University Press.

HAMM, R. 1991. Selection of verbal probabilities solution for some problems of verbal probability expression. Journal of Organizational Behavior and Human Decision Processes 48:193223.

HUBER, B., and HUBER, O. 1987. Development of the concept of comparative subjective probability. Journal of Experimental Child Psychology 44:304-316.

LARICHEV, O. 1987. Objective models and subjective decisions. Moscow: Nauka Publishing House. In Russian.

__ 1992. Cognitive validity in design of decision-aiding techniques. Journal of Multi-Criteria Decision Analysis 1(3): $27-138$.

LARICHEV, O., and MOSHKOVICH, H. 1997. Verbal decision analysis for unstructured problems. Boston: Kluwer Academic Publisher.

LARICHEV, O., BROWN, R., ANDRE'EVA, Y., and FLANDERS, N. 1995. Categorical decision analysis for environmental management: A Siberian gas distributing case. In: Caverni, J.P., Bar-Hillel, M., Barron, F.H., and Jungermann, H., eds. Contributions to decision making I. Amsterdam: North HollandElsevier. 255-286.

OSEREDKO, Y., LARICHEV, O., and MECHITOV, A. 1982. Main gas pipeline route selection problems, taking into consideration risk and uncertainty factors. In: Kunreuter, H., and Ley, E., eds. The risk analysis controversy. Berlin: SpringerVerlag. 91-101.

O’NEILL, D. 1994. The firecracker boys. New York: St. Martin's Press.

RAIFFA, H. 1968. Decision analysis: Introductory lectures on choices under uncertainty. Reading, Massachusetts: AddisonWesley.

RAPOPORT, A., WALLSTEN, T., EREV, I., and COHEN, B. 1990. Revision of opinion with verbally and numerically expressed uncertainties. Acta Psychologica 74:61-79.

WALLSTEN, T., BUDESCU, D., and ZWICK, R. 1993. Comparing the calibration and coherence of numerical and verbal probability judgements. Management Science 39:176-190.

ZECKHAUSER, R., KEENEY, R.L., and SEBENIUS, J.K., eds. 1996. Wise choices. Cambridge: Harvard Business School Press. 